This is the final peer-reviewed accepted manuscript of:

Alexandra Boini, Luigi Manfrini, Gianmarco Bortolotti, Luca Corelli-Grappadelli, Brunella Morandi "Monitoring fruit daily growth indicates the onset of mild drought stress in apple"

which has been published in final form in Scientia Horticulturae

Volume 256, 15 October 2019, n. 108520

The final published version is available online at:

https://doi.org/10.1016/i.scienta.2019.05.047

(C) 2019 Elsevier. This manuscript version is made available under the Creative Commons Attribution-NonCommercial-NoDerivs (CC BY-NC-ND) 4.0 International License (http://creativecommons.org/licenses/by-nc-nd/4.0/) 


\title{
Monitoring fruit daily growth indicates the onset of mild drought stress in apple
}

\author{
Alexandra Boini, Luigi Manfrini, Gianmarco Bortolotti, Luca Corelli-Grappadelli, \\ Brunella Morandi* \\ Department of Agricultural and Food Sciences (DISTAL), Alma Mater Studiorum - University of Bologna, Viale G. Fanin 46, 40127 Bologna, Italy
}

\begin{abstract}
A B S T R A C T
This work tests the possibility to monitor fruit growth as a potential physiological indicator for tree water status and productive performance in apple, for potential implementation in decision support systems for irrigation scheduling. Starting from 10 weeks after full bloom (WAFB), a wide range of plant water statuses was induced in a "Gala" apple orchard by applying different shading (with red-50\%, white-50\%, and black-20\% nets) and irrigation levels (severe-SS, moderate-MS and no-NS stress). For each net*irrigation treatment combination, midday stem water potential (mSWP) was assessed weekly, while fruit diameter variations were continuously monitored using automatic fruit gauges, from 10 WAFB until harvest. Leaf gas exchanges were also monitored at 14 and 16 WAFB. As expected, the different net*irrigation treatment combinations widely affected mSWP, leaf gas exchanges and fruit growth. On all dates of measurement, leaf gas exchanges were tightly correlated with mSWP, while daily fruit growth showed significant but weaker correlations with mSWP. In all cases, these relationships indicated the onset of drought stress below the threshold of about $1.2 \mathrm{~g}_{\text {fruit }}{ }^{-1}$ day $^{-1}$, which corresponded to mSWP below -1 MPa. Almost no correlation was found between mSWP and the other parameters derived from the fruit daily growth pattern (midday, maximum and minimum absolute growth rates (AGR) and fruit shrinkage). Based on these results, we can conclude that, although fruit daily growth rate is not related to mSWP as tightly as leaf gas exchanges, it represents a promising physiological indicator to be implemented in a decision support system for irrigation scheduling. Specific fruit growth thresholds indicating the onset of drought should be defined, depending on the orchard conditions and productive target.
\end{abstract}

Keywords:

Irrigation scheduling

Physiological indicator

Water relations

Fruit growth

Decision support systems

\section{Introduction}

Climate change is leading to high and severe constraints for irrigation, due to reduced water availability, increased evapotranspiration and water competition with other sectors (e.g. industry, civil uses etc.) (IPCC, 2014). Therefore, the development of appropriate strategies to increase plant water use efficiency and optimize irrigation scheduling is highly encouraged, worldwide.

To this extent, decision support systems (DSSs) represent promising tools to help growers optimizing their irrigation management, although a wide range of different approaches exists. The more traditional ones are based on models allowing to estimate crop evapotranspiration $\left(\mathrm{ET}_{\mathrm{c}}\right)$ and/or soil water balance (Allen et al., 1998), using data from weather stations as inputs. These systems are available online in different areas and give remote advice for irrigation scheduling, although sometimes they are not sufficiently accurate (Jones, 2004). Other DSSs are based on monitoring soil water status through soil moisture sensors (Jones, 2004). Both these approaches are indirect, as plant water needs are assessed by monitoring the surrounding environment while it would be highly desirable to schedule irrigation based on the actual plant water status, as this latter changes depending on several tree-related factors such as rootstock, source/sink ratio, phenological stage etc. (Naor, 2000, 2001a; Morandi et al., 2014b).

Plant water status can be assessed through various physiological parameters that, alone or in combination, provide very useful information on crop water requirements and physiological performances. However, discussion is still ongoing on which plant parameter is the more convenient in terms of reliability, cost and ease of monitoring

Abbreviations: AGR, fruit absolute growth rate; NS, not stressed; MS, moderately stressed; SS, severely stressed; W, trees under the white shading net (50\% shading); $\mathrm{R}$, trees under the red shading net (50\% shading); B, trees under the black hailing net (20\% shading); mSWP, midday Stem Water Potential; Pn, Photosynthesis; $\mathrm{g}_{\mathrm{s}}$, stomatal conductance; Tr, Transpiration; WAFB, weeks after full bloom

* Corresponding author.

E-mail address: brunella.morandi@unibo.it (B. Morandi). 
(Fernández et al., 2008; 2011a; 2011b; Fernández, 2017).

Stem water potential (Scholander et al., 1965) is probably the most reliable indicator for plant water status and it is often considered as a reference by the scientific community (Turner and Long, 1980; Naor, 2000, 2006a). Nevertheless, current protocols for its assessment are destructive and time consuming and are not suitable for measurements in commercial orchards. Other parameters include plant growth rate, leaf water potential, leaf relative water content (RWC), stomatal conductance and photosynthesis. All tend to be labour intensive and/or destructive. Remote sensing approaches can also be used in the detection and quantification of water stress, for example with thermal cameras able to monitor canopy temperature and thus transpiration rate (Jones, 2014). Most of these methods, though precise and accurate, are not considered user friendly and, as a matter of fact, they require sophisticated equipment, a high level of technical skills and need replicates for reliable outputs (Jones, 2004).

Researchers are currently working actively to provide solutions and applicable tools for plant-based DSSs. Recent improvements in sensing technology have promoted a new generation of sensors, enabling to continuously monitor some physiological parameters at plant level (Scalisi et al., 2017). For example, the measurement of the trunk sap flow can be easily automated and provides continuous and direct measurements of plant water flow (Fernández et al., 2008). Stem diameter shrinkage has been reported as a useful indicator for water stress (Goldhamer et al., 1999, 2000; Goldhamer and Fereres, 2001; Fereres and Goldhamer, 2003; Naor and Cohen, 2003; Intrigliolo and Castel, 2004), although it decreases with plant age, size and crop load (Fernández et al., 2011a). Leaf turgor pressure, measured by probes (Zimmerman et al., 2008), is a cheap and handy method, user-friendly for farmers without need of specific training (Padilla-Díaz et al., 2016).

However, the fruit represents the actual economic target of the production and its development is the consequence of many physiological processes occurring simultaneously at plant level, which are related both to the plant status and the environmental conditions. Therefore, it can be assumed that, if fruit growth is optimal, then all physiological processes going on at tree level are efficient.

Using the fruit as a monitoring target to evaluate the orchard performance, instead of leaves and stem, has been taken in consideration in the past, although these attempts did not find actual application in the field (Assaf et al., 1982; Forshey and Dominick, 1965; Furr and Taylor, 1939; Goel and Cohen, 1989). In modern decision support tools, the fruit is almost never considered as a physiological indicator for planning irrigation scheduling, probably due to the lack of user-friendly tools for monitoring its growth. In apple, pear and actinidia, digital calipers can be used to monitor fruit growing performances and provide a feedback about the appropriateness of the orchard management practices (www.hkconsulting.it). Furthermore, different types of fruit gauges to accurately monitor the daily pattern of fruit growth rate have been developed (Morandi et al., 2007; Thalheimer, 2016), and to date many solutions are commercially available, although some concerns related to the ease of use and cost effectiveness of these sensors still remain.

Fruit daily growth patterns are usually characterized by periods of shrinkage and swelling, leading to a permanent increase in fruit size at the end of the day (Fishman and Génard, 1998; Lang, 1990; Morandi et al., 2011a, 2012). The analysis of these periods could provide many real time information on the plant productive performances, and potentially on its physiological status. However, models are still lacking for the correct interpretation and commercial exploitation of this knowledge.

In apple, seasonal fruit growth in weight is described by an expolinear model, characterized by an initial stage (cell division) of increasing growth rates, followed by a second stage of constant growth rates (cell expansion) that last until harvest (Lakso et al., 1995). Fruit daily growth patterns change depending on the phenological stage. During the first half of the season, fruit growth is characterized by relatively high xylem functionality which may cause water backflows from fruit to stem, when leaf transpiration losses are very high. This determines periods of shrinkage during the midday hours, which are followed by periods of strong rehydration during the late afternoon and the night, when leaves reduce their stomatal conductance (Lang, 1990; Morandi et al., 2011b). On the contrary, during the second part of the season, fruit growth is sustained almost completely by phloem flow, while xylem vessels loose functionality. This determines a continuous increase in fruit diameter during the day, with a slight growth rate decrease during the central part of the day (Lang, 1990). However, regardless of the phenological stage, fruit growth is highly affected by stem water potential, as vascular flows to and from the fruit are clearly driven by water potential gradients between the stem and the fruit. As a consequence, when trees experience drought stress, their stem water potential is decreased, hence it becomes more difficult for the fruit to attract water from the vascular tissue and fruit growth rates tend to be reduced. This effect has been demonstrated via strong correlations between average stem water potential during the season and harvest fruit size (Naor et al., 1995, 1997, 2008). These considerations suggest that monitoring fruit growth may represent a sensitive indicator of plant water status as well as of the tree productive performances, especially during the cell expansion stage, when fruit growth rates are constant (Lakso et al., 1995).

The aim of this work is to test whether fruit daily growth rate represents a reliable indicator of plant water status to be used as a potential monitoring input in future DSSs for irrigation scheduling. To do this, variability in apple tree water status was induced during the fruit cell expansion stage, by modulating the water supply and the orchard light conditions and thus creating a wide range of different situations in terms of tree water status and fruit growth during a stage which is considered sensitive to water limitations and thus critical to reach acceptable yields and fruit sizes.

\section{Materials and methods}

\subsection{Plant material}

The trial was carried out in 2015 , at the experimental farm of the University of Bologna, located in Cadriano (Bologna) $\left(44^{\circ} 30^{\prime} \mathrm{N} ; 10^{\circ} 36^{\prime} \mathrm{E}\right.$; $27 \mathrm{~m}$ elevation), in an Imperial Gala apple orchard, grafted on M9. Trees were spaced $1 \times 3.8 \mathrm{~m}$ at a density of 3800 trees/ha and were undergoing a transition from the spindle to the solaxe training system (Lauri and Lespinasse, 2000). The orchard was irrigated using a drip irrigation system with 2.5 drippers per tree (the distance between emitters was $0.4 \mathrm{~m}$ ) with a flow of $2.0 \mathrm{~L} \mathrm{~h}^{-1}$ per dripper. Full bloom occurred on April 15th while fruit were harvested on Aug 10th, corresponding to 17 weeks after full bloom (WAFB). A weather station (Wi-Net s.r.l. Cesena, Italy) located in the field recorded temperature, relative humidity, solar radiation, wind speed and rain, every $15 \mathrm{~min}$. During the monitoring period (from $10 \mathrm{WAFB}$ to $16 \mathrm{WAFB}$ ), precipitations were around $20.3 \mathrm{~mm}$, in four events.

\subsection{Light management and irrigation treatments}

The orchard was divided in three plots where nets having different colour and shading percentages were applied right after fruit set: i) a black commercial hail net (20\% shading) (B), serving as control; ii) a red (R) 50\% shading net and iii) a pearl white (W) $50 \%$ shading net (Polysack Plastic Industries LTD).

Starting from 10 WAFB, within each light environment, three different irrigation treatments were applied, each to two orchard rows: i) no stress (NS) where trees were irrigated considering a $100 \% \mathrm{Et}_{\mathrm{c}} \mathrm{re}^{\mathrm{r}}$ placement (on the basis of $\mathrm{B}$ water requirements) and midday water potentials were maintained higher than $-1 \mathrm{MPa}$; ii) moderate stress (MS) where midday stem water potentials were maintained between -1 MPa and-1.5 MPa; iii) severe stress (SS) with midday SWP values 
below -1.5 MPa. In total, 9 different treatments derived from the combination of light and water management treatments: B-NS, B-MS, B-SS from the black $20 \%$ shading net; R-NS, R-MS, R-SS from the red $50 \%$ shading net; W-NS, W-MS, W-SS from the pearl white $50 \%$ shading net.

During the experiment a water balance $\left(\mathrm{ET}_{\mathrm{c}}=\mathrm{ET}_{0} \times \mathrm{K}_{\mathrm{c}}\right.$ - effective rainfall) was calculated, based on the weather data collected by the station in the field, with $\mathrm{ET}_{0}$ and $\mathrm{K}_{\mathrm{c}}$ representing the reference evapotranspiration and the crop coefficient, respectively. The PenmanMonteith method was used to determine $\mathrm{ET}_{0}$ (Allen et al., 1998), while $\mathrm{K}_{\mathrm{c}}$ values were derived based on midday canopy light interception (Auzmendi et al., 2010). $\mathrm{K}_{\mathrm{c}}$ was estimated as 0.6 between 7 and 8 WAFB and then increased to 0.9 between 9 and 16 WAFB (end of the experiment). Effective rainfall was considered the rain after subtracting $5 \mathrm{~mm}$ from total rainfall.

For each net, the six central rows were monitored (two rows randomly assigned for each irrigation treatment) leaving one or two rows of border trees between sectors to avoid any effect of the adjacent light environment. Within each row three homogeneous central trees (6 trees per net*irrigation treatment combination) were monitored and the first and last trees were considered border trees.

\subsection{Water relations}

During the experiment, midday stem water potential (mSWP) was measured weekly using a Scholander (Soil moisture Equipment Corp. Santa Barbara, U.S.A.) pressure chamber. For each tree, an internal leaf, close to the trunk, was selected and inserted in a black plastic bag covered by aluminium foil, at least $60 \mathrm{~min}$ before the measurement, to allow equilibration with the stem, according to the methodology described by McCutchan and Shackel (1992) and by Naor et al. (1995). For each date of measurement one leaf per tree was monitored on the six trees per treatment and means $( \pm \mathrm{SE})$ were then computed.

\subsection{Leaf gas exchanges}

At 14 and 16 WAFB, the main leaf gas exchange parameters (net photosynthesis, transpiration and stomatal conductance) were measured on one well exposed leaf per tree, on four leaves per treatment at solar noon, using an open circuit infra-red gas exchange system fitted with a LED light source (Li-COR 6400, LI-COR, Lincoln, Nebraska, USA). During each measurement, $\mathrm{CO}_{2}$ was set at $400 \mathrm{ppm}$ while the LED light source was set to the natural irradiance experienced by the leaves immediately before the measurements, in each net treatment.

\subsection{Fruit measurements}

The fruit diameter variations of four fruit per net*irrigation treatment combination were monitored from 10 to $16 \mathrm{WAFB}$, at $15 \mathrm{~min}$ intervals, using custom-built gauges interfaced to a wireless data-logger system. The gauges consisted of a light, stainless steel frame supporting a variable linear resistance transducer (Megatron Elektronik AG \& Co., Munchen, Germany). Temperature effects on the frame and the sensor were tested and showed negligible errors under normal field conditions (Morandi et al., 2007). The wireless data-logger system (Wi-Net s.r.l. Cesena, Italy) (Giorgetti et al., 2014) to which the gauges were connected was composed of wireless nodes, located on the topmost part of the pillar, at the beginning of the rows, to send a better signal to a central network node, which acted as a gateway towards the internet, through a general packet radio service (GPRS) modem. The monitored fruit (on three different trees per treatment) were homogeneous for size and position in the canopy.

At each recording time, diameter data (D) from all monitored fruit were converted to fresh weight (FW) using the following allometric equation:

$F W(g)=a^{*} D(m m)^{b}$ where $a$ is 0.0006 ( \pm SE 0.00005) and $b$ is 2.9029 ( \pm SE 0.0194). This equation was obtained by regressing diameter and weight data of about 300 fruit picked from various "Gala" apple orchards during the previous years. The $\mathrm{R}^{2}$ of the relationship was $>0.99$.

The conversion of the fruit growth data from diameter to weight was performed as apple fruit show a linear increase in weight, but not in diameter, whose growth rate progressively decreases as the fruit develop, during cell expansion (Lakso et al., 1995).

For each recording time ( $15 \mathrm{~min}$ intervals during the $24 \mathrm{~h}$ ), data from the 4 fruit per treatment were averaged and standard errors were computed.

\subsection{Harvest yield and mean fruit weight}

Harvest was performed when fruit achieved their commercial maturity to avoid possible interactions between fruit maturity and growth. Maturity was monitored using a DA-meter (Model DA-53500 meter, Turoni, Forlì, Italy). Two times before harvest, 20 fruits per each orchard sector and irrigation combination were sampled from several trees to determine their maturity index. Fruit were harvested when the mean output of the DA-meter had a value lower than 0.9, indicative of mature 'Gala' apple (Costamagna et al., 2013). Harvest was performed on the 6 selected trees per each net*irrigation treatment combination. For each tree, crop load (total number of fruit per tree), total and marketable yield $\left(\mathrm{Kg}_{\text {tree }}{ }^{-1}\right)$ as well as mean fruit weight $(\mathrm{g})$ were determined. Marketable yield was calculated taking into consideration fruit with a diameter higher than $65 \mathrm{~mm}$.

\subsection{Correlation study}

In correspondence with the day when midday stem water potentials were measured, fruit net daily growth, midday AGR, maximum AGR, minimum AGR and fruit daily shrinkage (or "fruit central day growth") were also calculated for every net*irrigation level combination.

Fruit net daily growth was calculated as the difference in fresh weight recorded at midnight between two following days. Maximum AGR and minimum AGR were the maximum and minimum instantaneous fruit growth rates (mg fruit ${ }^{-1} \mathrm{~min}^{-1}$ ) recorded during the $24 \mathrm{~h}$, respectively. Midday AGR was the instantaneous fruit growth rate ( $\mathrm{mg}$ fruit ${ }^{-1} \mathrm{~min}^{-1}$ ) recorded at the time of mSWP determination. Fruit daily shrinkage (or "fruit central day growth") was calculated as the difference between the maximum and the minimum fresh weights recorded between 06:00 and 17:00 h.

At 11, 13, 14 and 16 WAFB the treatment averages for these fruitderived parameters were related to midday stem water potential. Furthermore, at 14 and 16 WAFB, fruit-derived parameters were related to leaf gas exchanges: photosynthesis, stomatal conductance and transpiration. Furthermore, harvest marketable yield and mean fruit weight were related to the average seasonal mSWP (calculated as the average within all dates of measurements) recorded during the experiment; while mean fruit weight was related to the average daily fruit growth.

All relations were then analysed and the correlation coefficients, slopes and p-values reported.

\subsection{Statistical analysis}

Averages of midday stem water potential, leaf gas exchanges and fruit-derived parameters were separated using a two-way analysis (ANOVA) with irrigation level and net as factors of the analysis. SNK's test (Zar, 1984) was then applied to compare the averages among the different shading and irrigation treatments. 



NS - - MS

Fig. 1. Seasonal patterns of midday stem water potential for B treatments (A), R treatments (B) and $W$ treatments (C), with the relative irrigation treatments. The thick lines represent non-stressed treatments (NS), the dashed ones moderate stressed treatments (MS) and the thin lines the severely stressed treatments (SS). Symbols represent the mean \pm SE of six leaves. Different letters indicate significant difference at $\mathrm{P}<0.05$. No letters indicate no significant difference. 


\section{Results}

\subsection{Water relations}

Since the start of irrigation, at 10 WAFB, until harvest, NS, MS and SS treatments received around 153, 48 and $1.35 \mathrm{~mm}$ of irrigation, respectively. In all light conditions, mSWP progressively decreased during the season and showed increasing differences among irrigation levels (Fig. 1). As for the experimental set-up NS trees always maintained significantly higher mSWP, never going below $-1.2 \mathrm{MPa}$ in any of the light treatments. MS treatments maintained intermediate values between -1 and $-1.5 \mathrm{MPa}$ while SS treatments maintained significantly lower values under all light conditions, reaching a minimum of $-2.1 \mathrm{MPa}$, at $14 \mathrm{WAFB}$, under the control hail net. Furthermore, the different net*irrigation treatment combinations allowed to reach a wide range of tree water statuses, especially from 13 WAFB on, with mSWP values ranging between -1.02 and $-1.95 \mathrm{MPa}$, between -0.98 and $-2.08 \mathrm{MPa}$ and between $-1,01$ and $-1.91 \mathrm{MPa}$ at 13,14 and $16 \mathrm{WAFB}$, respectively (Fig. 1).

\subsection{Leaf gas exchanges}

The different net*irrigation treatment combinations affected leaf gas exchanges and induced a wide range in the average values among irrigation treatments. In both dates, NS trees maintained the highest values either in photosynthesis (Fig. 2), stomatal conductance and transpiration (data not shown), followed by MS and SS trees. Under all nets, high stress conditions induced an almost complete stomatal closure $\left(0.05\right.$ and $0.06 \mathrm{~mol} \mathrm{~m}^{-2} \mathrm{~s}^{-1}$ at 14 and $16 \mathrm{WAFB}$, respectively) while photosynthesis decreased accordingly, of more than $70 \%$ from NS to SS treatments (Fig. 2). On the contrary, no differences were recorded among the different nets (Fig. 2).

\subsection{Fruit measurements}

Fruit growth measurements showed wide variations in fruit growth rate during the $24 \mathrm{~h}$ (Fig. 3), with periods of rapid growth, usually recorded in the late afternoon and during the night, followed by periods of reduced or even negative growth rates, during the central part of the day. At 11 WAFB, hourly variations in fruit growth rate were wider, with periods of shrinkage, from 9:00 to 15:00 h, (Fig. 3a-b-c) and swelling, from 15:00 to ca. 8:00 h. As the fruit developed, shrinkage was substituted by a steady state (at 13 WAFB) (Fig. 3d-e-f) and then by a simple reduction in fruit growth rate (16WAFB) (Fig. 3g-h-i) during the central hours of the day. During the whole experiment, net and irrigation treatments strongly affected fruit growth rate both on a daily basis and at different times during the day, showing a wide range of responses. In general, SS treatments showed the lowest fruit daily growth rates, regardless of the monitoring period with values always below $1 \mathrm{~g}$ fruit ${ }^{-1} \mathrm{~d}^{-1}$ (Fig. 3a-d-g).

\subsection{Harvest yield and mean fruit weight}

As expected, the net*irrigation treatment application induced a wide range of different productive performances, with marketable yield values ranging from 1.9 to $11.52 \mathrm{~kg}^{-1} \mathrm{tre}^{-1}$ and mean fruit weight values ranging from 100 to $146 \mathrm{~g}$. At harvest, trees under the $\mathrm{R}$ and $\mathrm{W}$ net had a total crop load of $92 \pm 9$ and $85 \pm 10$ fruit tree ${ }^{-1}$, respectively; while trees under the $B$ hail net showed a higher crop load, reaching an average of $125 \pm 7$ fruit tree ${ }^{-1}$. Mean fruit weight was significantly affected by the irrigation treatment with significantly lower values in the SS trees. Similarly, irrigation treatments widely affected marketable yield, with average values $( \pm$ SE) of $9.9 \pm 0.79,6.9 \pm 0.48$ and $2.6 \pm 0.48 \mathrm{~kg}$ tree $^{-1}$ for NS, MS and SS treatments, respectively. On the contrary, marketable yield was not affected by the different nets, with average values of $6.8 \pm 1.3,5.9 \pm 0.7$ and $7 \pm 1 \mathrm{~kg}^{-1}$ tree $^{-1}$ in the $\mathrm{B}, \mathrm{R}$ and $\mathrm{W}$ trees, respectively.

\subsection{Correlation study}

A significant negative relationship between daily fruit growth and mSWP was found (Fig. 4; Table 1), with $r$ values around or above 0.70 . On the contrary, no correlation was found between the other fruit-derived parameters (midday AGR, max AGR, min AGR, fruit shrinkage) and mSWP, except at 16WAFB, when fruit central day growth showed a positive relationship with $\mathrm{mSWP}(\mathrm{r}=0.66)$.

Concerning leaf gas exchange parameters, on all dates they were highly related to mSWP (Fig. 5; Table 1), with decreasing photosynthesis (Fig. 5a-b), stomatal conductance (Fig. 5c-d) and transpiration (Fig. 5e-f) in trees with lower mSWP values ( $r>0.9$; $\mathrm{P}<0.01$ ). Fruit daily growth was positively related to leaf gas exchanges both at 14 and 16 WAFB, but not the other fruit-related parameters, such as midday AGR, max AGR, min AGR and fruit shrinkage / fruit central day growth (Table 1). Harvested marketable yield and mean fruit weight were linearly related to seasonal average mSWP $(r=0.91)$, with higher yield and fruit weight in correspondence with less negative mSWP (Fig. 6a and b). Similarly, mean fruit weight was positively and linearly related with the average fruit daily growth recorded during the cell expansion stage (Fig. 7).

\section{Discussion}

Conditioning the orchard light environment, while modulating the irrigation supply, allowed to obtain a range of different conditions in
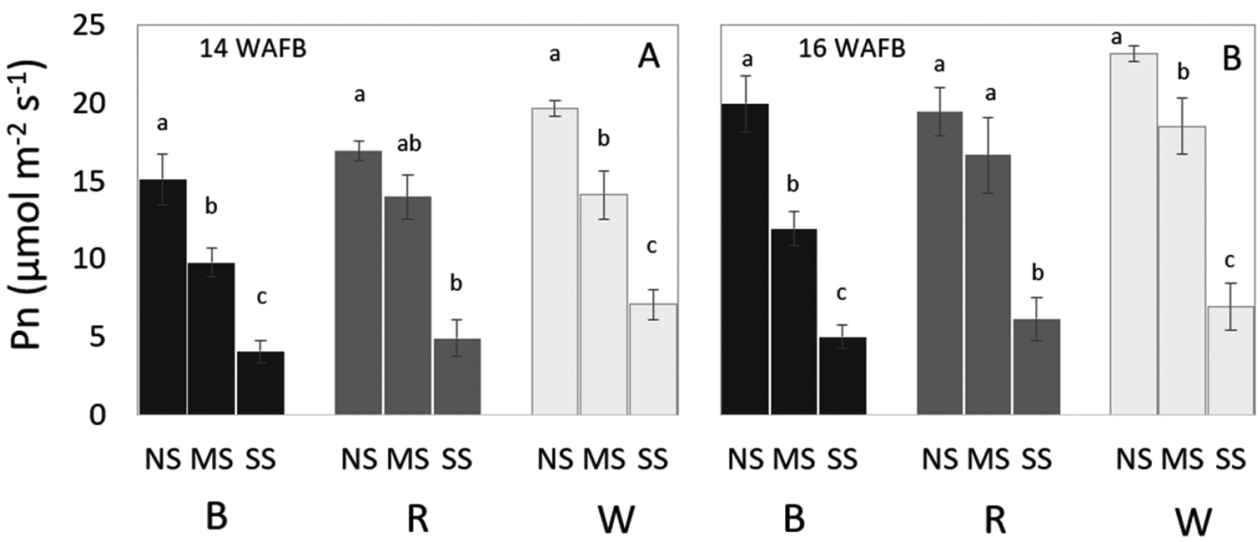

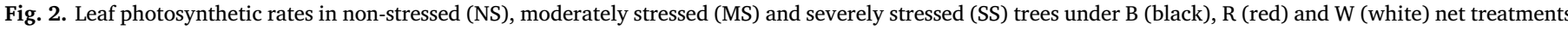

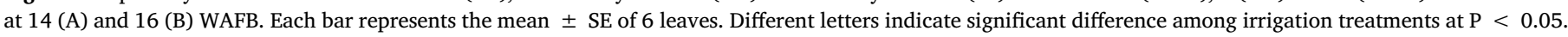




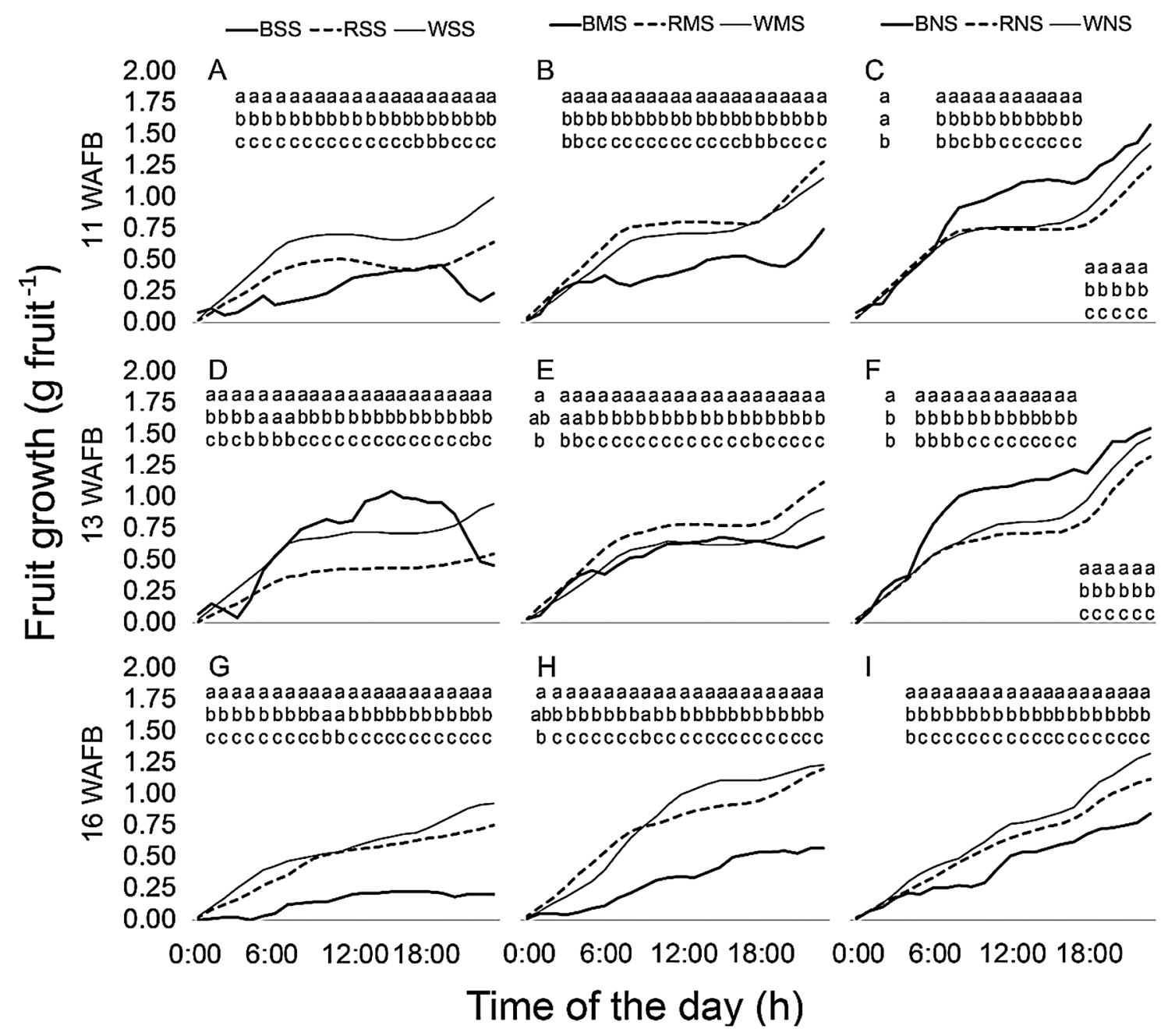

Fig. 3. Fruit daily growth patterns under B (bold lines), R (dashed lines) and $W$ (normal lines) net treatments in severely (A, D, G), moderate (B, E, H) and nonstressed (C, F, I) conditions, at 11 (A-C) 13 (D-F) and 16 (G-I) WAFB. Each line represents the mean of four fruit. Different letters indicate significant difference at $\mathrm{P}<0.05$. No letters indicate no significant difference.

terms of tree water status, with mSWP ranging from about -1 MPa down to $-2 \mathrm{MPa}$, (Fig. 1), thanks to the little precipitations recorded during the season. As apple is very sensitive to water stress during the cell expansion stage (Naor, 2012), variations in mSWP induced by the ne$t$ *irrigation treatment combinations led to a wide range of different productive performances, with harvest mean fruit weight and marketable yield showing a positive relationship with mSWP (Fig. 6). Similar results were found by Naor et al. (1999; 2001a) who showed how higher stem water potentials during the season induced commercial yields in peach and pear.

In conditions of moderate to high drought stress, stem water potentials and leaf gas exchanges were reduced and fruit growth took benefit from the presence of stronger shading, showing higher daily growth rates under $50 \%$ shading nets, compared to the control $(20 \%$ shading net), on all dates monitored (Fig. 3). Although the scope of this paper is not to investigate the effect of shading nets, these findings are in agreement with results found by Lopez et al. (2018) in the same orchard, where in a situation of water stress the presence of shading led to an increase in fruit production, with no decrease in photosynthesis, compared to full light conditions. Such positive responses of fruit growth to shading might be attributed to the less negative stem water potential recorded in these conditions (Fig. 1) and to the lower VPDs typical of shaded environments (Morandi et al., 2016).

Midday stem water potential is considered by literature one of the most reliable references for tree water status, as it usually reflects very well the soil water availability, the VPD and the tree physiological performances in terms of leaf gas exchange and fruit size (Naor et al., 1997, 1999, 2001a, 2001b, 2006b). This is confirmed by the positive and strong relationships found between mSWP and either photosynthesis, stomatal conductance and transpiration (Fig. 5), with trees subjected to stress showing decreasing leaf gas exchanges (Fig. 2) and thus confirming midday stem water potential as a reliable reference parameter for tree water status.

However, in commercial orchards, fruit are the real target of the production and maximising photosynthesis may not always represent the most resource-efficient solution in terms of productivity, as not all carbohydrates are allocated to fruit sinks, due to the strong competition with the growing shoots (Dejong, 1999). Therefore, physiological indicators for plant water status such as stem water potential, leaf photosynthesis or stomatal conductance may not necessarily be highly related to tree productive performances, as this latter also depends on other management factors, such as the canopy source/sink ratio.

It is well known how vascular flows sustaining fruit growth are driven by water potential gradients between the stem and the fruit (Fishman and Gènard, 1998) and, for a given fruit water potential, the higher the stem water potential, the higher the relative stem-to-fruit gradient. Due to this likely "cause-effect" relationship among stem water potential and fruit vascular inflows, a positive linear relationship was found between mSWP and fruit daily growth, regardless of the monitored period (Fig. 4a-d). These relationships show how, regardless 
A. 11 WAFB

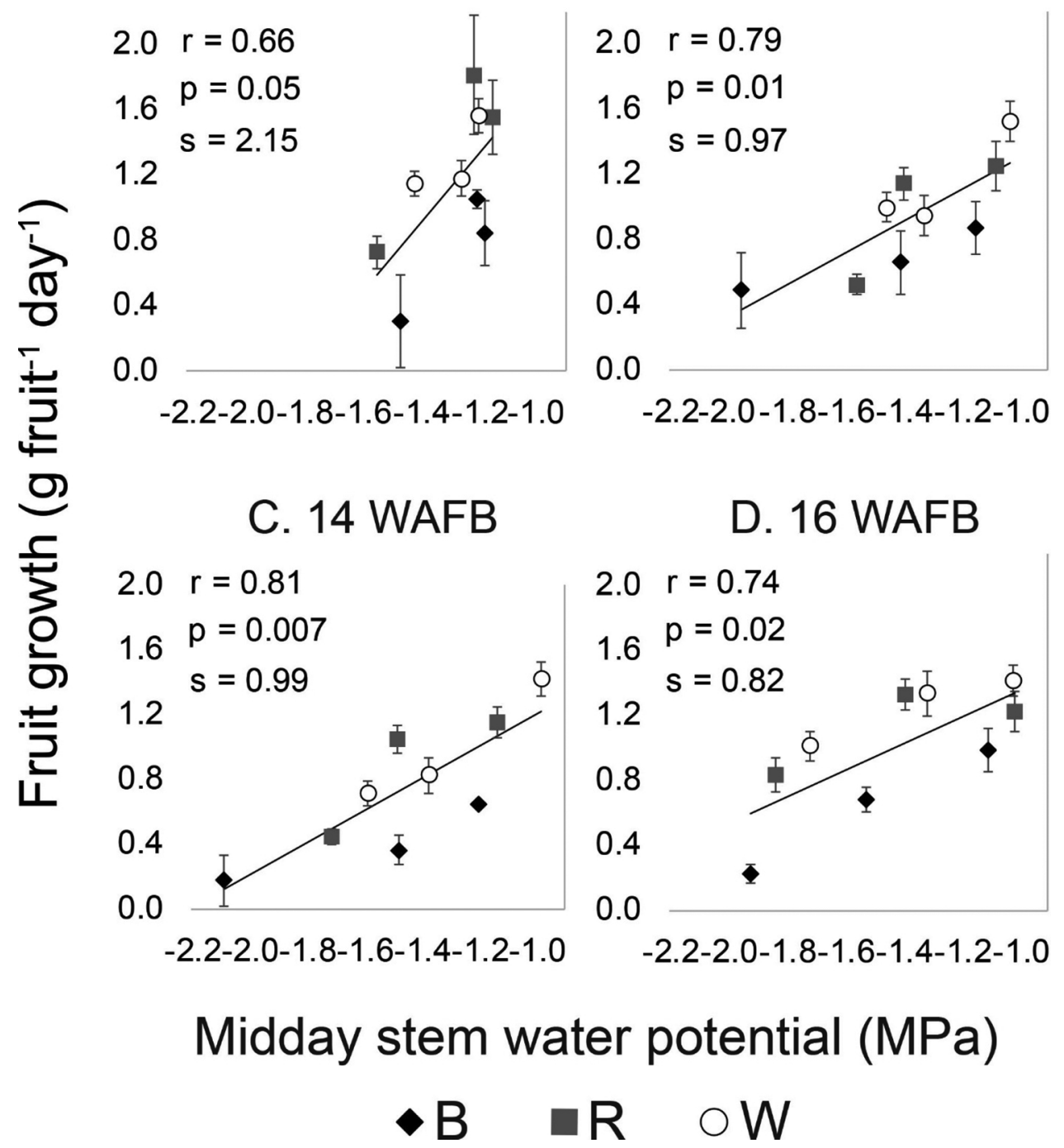



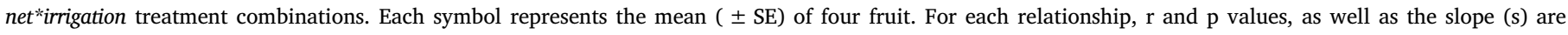
reported.

Table 1

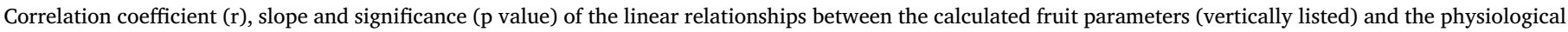
parameters (horizontally listed), at 14 and 16 WAFB.

\begin{tabular}{|c|c|c|c|c|c|c|c|c|c|c|c|c|c|}
\hline & & \multicolumn{12}{|c|}{ Midday physiological parameters } \\
\hline & & \multicolumn{3}{|c|}{ Photosynthesis } & \multicolumn{3}{|c|}{ Conductance } & \multicolumn{3}{|c|}{ Transpiration } & \multicolumn{3}{|c|}{ mSWP } \\
\hline & & $\mathrm{r}$ & slope & $\mathrm{p}$ & $\mathrm{r}$ & slope & $\mathrm{p}$ & $\mathrm{r}$ & slope & $\mathrm{p}$ & $\mathrm{r}$ & slope & $\mathrm{p}$ \\
\hline & & $14 \mathrm{~W}$ & FB & & & & & & & & & & \\
\hline \multirow[t]{7}{*}{ Fruit parameters } & Midday AGR & 0.32 & $-2.74 \mathrm{E}+03$ & 0.39 & 0.27 & $-3.05 E+01$ & 0.47 & 0.29 & $-1.02 \mathrm{E}+03$ & 0.45 & 0.54 & $-2.82 \mathrm{E}+02$ & 0.13 \\
\hline & Midday RGR & 0.32 & $-2.59 \mathrm{E}+05$ & 0.40 & 0.27 & $-2.88 \mathrm{E}+03$ & 0.48 & 0.28 & $-9.56 \mathrm{E}+04$ & 0.46 & 0.53 & $-2.55 E+04$ & 0.13 \\
\hline & Max AGR & 0.00 & $4.74 \mathrm{E}+02$ & 0.99 & 0.01 & $8.48 \mathrm{E}+00$ & 0.98 & 0.00 & $2.63 \mathrm{E}+02$ & 0.99 & 0.04 & $-9.22 \mathrm{E}+00$ & 0.58 \\
\hline & Min AGR & 0.37 & $7.93 E+02$ & 0.32 & 0.33 & $9.22 \mathrm{E}+00$ & 0.38 & 0.32 & $2.87 \mathrm{E}+02$ & 0.39 & 0.46 & $6.17 \mathrm{E}+01$ & 0.19 \\
\hline & Net gained grammes & 0.82 & $1.16 \mathrm{E}+01$ & $<0.01$ & 0.79 & $1.50 \mathrm{E}-01$ & 0.01 & 0.78 & $4.72 \mathrm{E}+00$ & 0.01 & 0.86 & $7.08 \mathrm{E}-01$ & $<0.01$ \\
\hline & FShrinkage & 0.14 & $-9.24 \mathrm{E}+00$ & 0.72 & 0.10 & $-1.00 \mathrm{E}-01$ & 0.80 & 0.10 & $-3.28 \mathrm{E}+00$ & 0.79 & 0.42 & $-1.01 \mathrm{E}+00$ & 0.43 \\
\hline & & $16 \mathrm{~W}$ & FB & & & & & & & & & & \\
\hline \multirow[t]{6}{*}{ Fruit parameters } & Midday AGR & 0.49 & $5.67 \mathrm{E}+03$ & 0.17 & 0.53 & $1.40 \mathrm{E}+02$ & 0.14 & 0.52 & $3.94 \mathrm{E}+03$ & 0.15 & 0.46 & $4.19 \mathrm{E}+02$ & 0.21 \\
\hline & Midday RGR & 0.39 & $5.19 \mathrm{E}+05$ & 0.29 & 0.39 & $1.18 \mathrm{E}+04$ & 0.30 & 0.40 & $3.46 \mathrm{E}+05$ & 0.28 & 0.33 & $3.49 \mathrm{E}+04$ & 0.37 \\
\hline & Max AGR & 0.48 & $1.26 \mathrm{E}+03$ & 0.19 & 0.49 & $3.00 \mathrm{E}+01$ & 0.17 & 0.49 & $8.54 \mathrm{E}+02$ & 0.17 & 0.47 & $9.94 \mathrm{E}+01$ & 0.19 \\
\hline & Min AGR & 0.05 & $-1.04 \mathrm{E}+02$ & 0.97 & 0.11 & $-4.87 \mathrm{E}+00$ & 0.87 & 0.11 & $-1.47 \mathrm{E}+02$ & 0.85 & 0.07 & $-1.08 \mathrm{E}+01$ & 0.94 \\
\hline & Net gained grammes & 0.74 & $8.26 \mathrm{E}+00$ & 0.01 & 0.68 & $1.75 \mathrm{E}-01$ & 0.02 & 0.68 & $4.95 \mathrm{E}+00$ & 0.03 & 0.70 & $6.24 \mathrm{E}-01$ & 0.02 \\
\hline & FShrinkage & 0.66 & $2.07 \mathrm{E}+01$ & 0.05 & 0.67 & $4.80 \mathrm{E}-01$ & 0.05 & 0.67 & $1.37 \mathrm{E}+01$ & 0.05 & 0.66 & $1.64 \mathrm{E}+00$ & 0.05 \\
\hline
\end{tabular}


14 WAFB
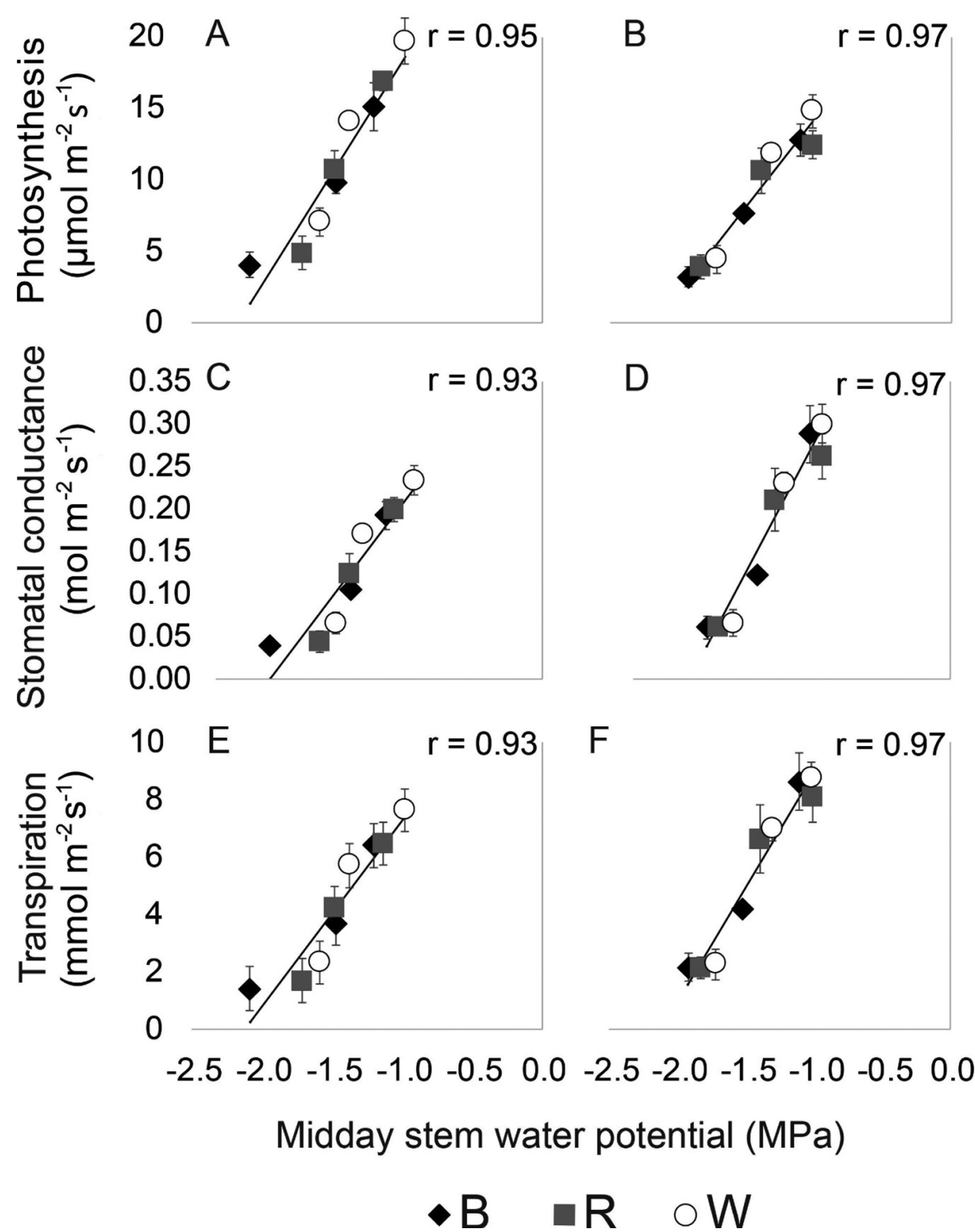

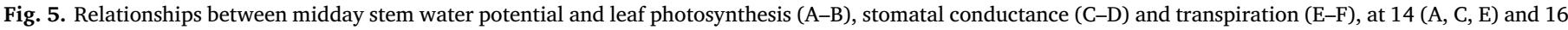

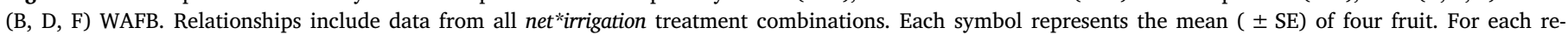
lationship, $\mathrm{r}$ is reported.

of the date of measurement, daily fruit growths below $1.2-1.3 \mathrm{~g} \mathrm{day}^{-1}$ correspond to MSWP values below $-1 \mathrm{MPa}$ (Fig. 4), which is considered the threshold below which a mild drought stress can appear, in apple (Naor et al., 1995; Naor, 2012; Lopez et al., 2018). Therefore, in our experimental conditions, fruit growth below $1.2-1.3 \mathrm{~g}_{\text {fruit }^{-1}}$ day $^{-1}$ can indicate the onset of drought stress and thus the need to increase irrigation. As apple fruit grow in weight is constant from the beginning of cell expansion until harvest (Lakso et al., 1995), such reference value does not change from 11 to 16 WAFB (Fig. 4). Clearly, this value is referred to the specific conditions (in terms of orchard age, crop load and nutritional status etc.) of the orchard where the experiment was conducted and, therefore, it can vary for other orchards and varieties.

The other physiological parameters derived from the analysis of the fruit daily growth pattern, such as midday, max and min AGR and daily shrinkage (or central day growth), did not show any consistent relationship with mSWP, thus indicating a lower application potential for these parameters. These data are in agreement with Morandi et al. (2016), where a similar study was conducted in the same orchard but in a previous year and, due to the frequent rainy events, stem water potential never reached values below -1.2 MPa, with correspondent fruit growth rates of about $1.3 \mathrm{~g} \mathrm{~d}^{-1}$.

The correlation between fruit daily growth and mSWP was not as tight as the one between leaf gas exchanges (photosynthesis and stomatal conductance) and mSWP (Table 1), where extremely high $\mathrm{r}$ values were found (Fig. 5). This might be due to the fact that, while stomatal opening directly responds to water availability, fruit growth is probably less dependent on the xylem contribution at this stage of development. In fact, after about 55 days after full bloom, Gala apples tend to show disruptions in the fruit xylem vessels (Dražeta et al., 2004) with consequent losses in xylem functionality. Therefore, from 10 

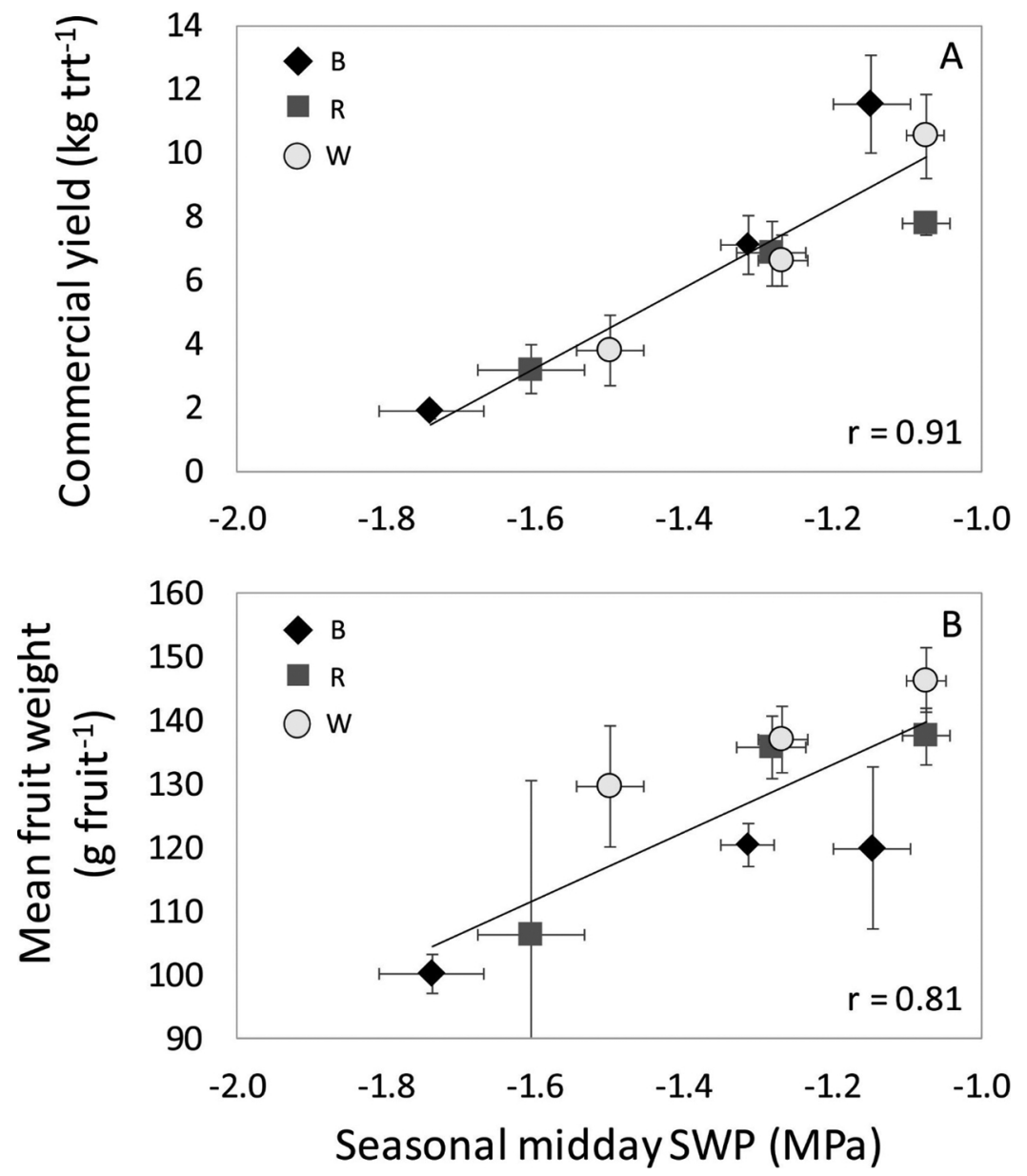


from all net*irrigation treatment combinations.



Fig. 7. Relationships between seasonal mean daily fruit growth ( $g$ fruit ${ }^{-1} \mathrm{~d}^{-1}$ ) and harvest fruit size $\left(\mathrm{g}\right.$ fruit $^{-1}$ ). The relationship includes data from all $n e-$ $t$ *irrigation treatment combinations.

WAFB onwards, apple fruit growth may be less dependent on mSWP compared to leaf gas exchanges. In fact, at this time of the season apple fruit growth is almost totally sustained by phloem flow (Lang, 1990), whose unloading process is known to be apoplastic (Zhang et al., 2004), thus actively carried out by specific carbohydrates transporters that may reduce the dependence on hydrostatic pressure gradients along the vascular path (Münch, 1930), for the fruit to grow. This is probably the reason why fruit growth was relatively less sensitive to changes in mSWP compared to leaf gas exchanges, although further studies would be needed to clarify this aspect.
On the contrary, average fruit growth rates during the season showed a tight correlation with final fruit size (Fig. 7), thus confirming how monitoring fruit growth rate may represent a viable alternative to assess tree productive performance and may provide useful feedbacks to drive irrigation scheduling, although the optimal fruit growth rate may change with variety, orchard conditions and productive target.

In recent years, monitoring the growth rate of a significant sample of fruit has been used as decision support tool for orchard management (mainly irrigation and crop load management) (www.hkconsulting. com). This protocol, which is commercially adopted, is limited by the need to monitor fruit growth manually, using a digital calliper, so that feedbacks to the grower are given at large time intervals, of about seven-ten days. The adoption of automatic fruit gauges would surely facilitate fruit growth monitoring, avoiding the necessity for manual measurements, whereas allowing sudden corrective actions when fruit growth rate is reduced at a given critical threshold.

However, statistical representation in the field remains a critical issue, as the higher the number of monitored fruit, the more reliable the measurement. Geostatistical approaches are required to assess the minimum number of fruit gauges needed to represent the "within orchard" and "within tree" variabilities, as well to correctly choose fruit samples within the orchard and the tree.

\section{Conclusions}

Results from this paper show how, in apple, the continuous monitoring of fruit growth rate with automatic fruit gauges may represent a promising tool to be implemented in a decision support system for 
irrigation scheduling. To this end, fruit daily growth rate represents the fruit parameter showing the best correlation with plant water status, thus having the potential to be used as a reference trait for irrigation scheduling.

In our experimental conditions, a fruit daily growth rate of $1.2-1.3 \mathrm{~g}$ day $^{-1}$ represented the threshold, indicating the onset of a mild water stress and thus the need for irrigation, although such threshold may change depending on the orchard conditions and productive target.

Further studies are needed to validate fruit growth thresholds to be used for drought stress detection, as well as the development of geostatistical approaches to rationally address the existing variability within the orchard and the tree.

\section{Acknowledgements}

This work was partly supported by the ARIMNET research program: "APMed - Apple and Peach in Mediterranean orchards - Integrating tree water status and irrigation management for coping with water scarcity and aphid control". We also thank Marco Zibordi and Emanuele Pierpaoli for technical support in the data collection.

\section{References}

Allen, R.G., Pereira, L.S., Raes, D., Smith, M., 1998. Crop evapotranspiration. Guidelines for computing crop water requirements. FAO Irrigation and Drainage Paper no 56. pp. 300.

Assaf, R., Levin, I., Bravdo, B., 1982. Apple fruit growth as a measure of irrigation control. HortScience 17, 59-61.

Auzmendi, I., Mata, M., Lopez, G., Jirona, J., Marsal, J., 2010. Intercepted radiation by apple canopy can be used as a basis for irrigation scheduling. Agric. Water Manag. 98, 886-892.

Costamagna, F., Giordani, L., Costa, G., Noferini, M., 2013. Use of AD Index to define harvest time and characterize ripening variability at harvest in 'Gala' Apple. Acta Hortic. 998, 117-123.

Dejong, T.M., 1999. Developmental and environmental control of dry-matter partitioning in peach. HortScience 34, 1037-1040.

Dražeta, L., Lang, A., Hall, A.J., Volz, R.K., Jameson, P.E., 2004. Causes and effects of changes in xylem functionality in apple fruit. Ann. Bot. 93 (3), 375-382.

Fereres, E., Goldhamer, D.A., 2003. Suitability of stem diameter variations and water potential as indicators for irrigation scheduling of almond trees. J. Hortic. Sci. Biotech. 78 (2), 139-144.

Fernández, J.E., Green, S.R., Caspari, H.W., Diaz-Espejo, A., Cuevas, M.V., 2008. The use of sap flow measurements for scheduling irrigation in olive, apple and Asian pear trees and in grapevines. Plant Soil 305 (1-2), 91-104.

Fernández, J.E., Torres-Ruiz, J.M., Diaz-Espejo, A., Montero, A., Álvarez, R., Jiménez, M.D., Cuerva, J., Cuevas, M.V., 2011a. Use of maximum trunk diameter measurements to detect water stress in mature' Arbequina' olive trees under deficit irrigation. Agric. Water Manag. 98 (12), 1813-1821.

Fernández, J.E., Moreno, F., Martin-Palomo, M.J., Cuevas, M.V., Torres-Ruiz, J.M., Moriana, A., 2011b. Combining sap flow and trunk diameter measurements to assess water needs in mature olive orchards. Environ. Exp. Bot. 72 (2), 330-338. https:// doi.org/10.1016/j.envexpbot.2011.04.004.

Fernández, J.E., 2017. Plant-based methods for irrigation scheduling of woody crops Horticulturae 3, 35. https://doi.org/10.3390/horticulturae3020035.

Fishman, S., Génard, M., 1998. A biophysical model of fruit growth: simulation of seasonal and diurnal dynamics of mass. Plant Cell Environ. 21, 739-752.

Forshey, C.G., Dominick, B.A., 1965. Irrigation of Apples in the Hudson Valley. N.Y. State Agr. Expt. Sta. Bul., pp. 809.

Furr, J.R., Taylor, C.A., 1939. Growth of Lemon Fruits in Relation to Moisture Content of the Soil. U.S. Dept. Agr. Tech.

Giorgetti, A., Lucchi, M., Tavelli, E., Chiani, E., Dardar, D., 2014. Design and deployment of a wireless sensor network for landslide risk management. IEEE WiMob 2014 Workshop on Emergency Networks for Public Protection and Disaster Relief. Bul., pp. 640.

Goel, A., Cohen, A., 1989. Analysis of fruit growth in grapefruit as affected by irrigation intervals. Sci. Hortic. 39, 223-233.

Goldhamer, D.A., Fereres, E., Mata, M., Girona, J., Cohen, M., 1999. Sensitivity of continuous and discrete plant and soil water status monitoring in peach trees subjected to deficit irrigation. J. Am. Soc. Hortic. Sci. 124, 437-444.

Goldhamer, D.A., Soler, M., Salinas, M., Fereres, E., Cohen, M., Girona, J., Mata, M., 2000. Comparison of Continuous and Discrete Plant-based Monitoring for Detecting Tree Water Deficits and Barriers to Grower Adoption for Irrigation Management. Acta Hortic. 537, 431-445

Goldhamer, D.A., Fereres, E., 2001. Irrigation scheduling protocols using continuously recorded trunk diameter measurements. Irrig. Sci. 20 (3), 115-125.

Intrigliolo, D.S., Castel, J.R., 2004. Continuous measurement of plant and soil water status for irrigation scheduling in plum. Irrig. Sci. 23, 93-102.

IPCC (Intergovernmental Panel on Climate Change), et al., 2014. Summary for policymakers. In: Field, C.B. (Ed.), Climate Change 2014: Impacts, Adaptation, and
Vulnerability. Part A: Global and Sectoral Aspects. Cambridge University Press, Cambridge, pp. 1-32.

Jones, H.G., 2004. Irrigation scheduling: advantages and pitfalls of plant-based methods. J. Exp. Bot. 55 (407), 2427-2436.

Jones, H.G., 2014. Remote sensing of plant stresses and its use in irrigation management. Acta Hortic. 1038, 239-248.

Lakso, A.N., Grappadelli, L.C., Barnard, J., Goffinet, M.C., 1995. An expolinear model of the growth pattern of the apple fruit. J. Hortic. Sci. 70 (3), 389-394.

Lang, A., 1990. Xylem, phloem and transpiration flows in developing apple fruits. J. Exp. Bot. 41 (6), 645-651. https://doi.org/10.1093/jxb/41.6.645.

Lauri, P.E., Lespinasse, J.M., 2000. The vertical axis and solaxe systems in France. Acta Hortic. 513, 287-296.

Lopez, G., Boini, A., Manfrini, L., Torres-Ruiz, J.M., Pierpaoli, E., Zibordi, M., Losciale, P., Morandi, B., Corelli-Grappadelli, L., 2018. Effect of shading and water stress on light interception, physiology and yield of apple trees. Agric. Water Manag. 210, 140-148.

McCutchan, H., Shackel, K.A., 1992. Stem-water Potential as a Sensitive Indicator of Water Stress in Prune Trees (Prunus domestica L. cv. French). J. Am. Soc. Hortic. Sci. 117 (4), 607-611.

Morandi, B., Boselli, F., Boini, A., Manfrini, L., Corelli, L., 2016. The fruit as a potential indicator of plant water status in apple. Acta Hortic. 1150, 83-90. https://doi.org/10. 17660/ActaHortic.2017.1150.12.

Morandi, B., Losciale, P., Manfrini, L., Zibordi, M., Pierpaoli, E., Grappadelli, L.C., 2012. How changes in weather conditions affect growth, vascular and transpiration flows in young apple fruit. Acta Hortic. 951, 139-146.

Morandi, B., Zibordi, M., Losciale, P., Manfrini, L., Pierpaoli, E., Grappadelli, L.C., 2011a. Shading decreases the growth rate of young apple fruit by reducing their phloem import. Sci. Hortic. 127 (3), 347-352.

Morandi, B., Losciale, P., Manfrini, L., Zibordi, M., Grappadelli, L.C., 2011b. Crop load alters water potential and daily vascular flows in peach fruit. Acta Hortic. 903, $821-826$.

Morandi, B., Manfrini, L., Zibordi, M., Noferini, M., Fiori, G., Corelli Grappadelli, L., 2007. A low-cost device for accurate and continuous measurement of fruit growth. HortScience 42, 1380-1382.

Münch, E., 1930. Die Stoffbewegungen in der Pflquanze. Gustav Fischer, Jena.

Naor, A., Klein, I., Doron, I., 1995. Stem water potential and apple size. J. Am. Soc. Hortic. Sci. 120 (4), 577-582.

Naor, A., Klein, I., Doron, I., Gal, Y., Ben-David, Z., Bravdo, B., 1997. The effect of irrigation and crop load on stem water potential and apple fruit size. J. Hortic. Sci. 72 (5), 765-771.

Naor, A., Klein, I., Hupert, H., Grinblat, Y., Peres, M., Kaufman, A., 1999. Water stress and crop level interactions in relation to nectarine yield, fruit size distribution, and water potentials. J. Am. Soc. Hortic. Sci. 124 (2), 189-193.

Naor, A., 2000. Midday stem water potential as a plant water stress indicator for irrigation scheduling in fruit trees. Acta Hortic. 537, 447-454.

Naor, A., 2001a. Irrigation and crop load influence fruit size and water relations in fieldgrown "Spadona" pear. J. Am. Soc. Hortic. Sci. 126 (2), 252-255.

Naor, A., Hupert, H., Greenblat, Y., Peres, M., Kaufman, A., Klein, I., 2001b. The response of nectarine fruit size and midday stem water potential to irrigation level in stage III and crop load. J. Am. Soc. Hortic. Sci. 126, 140-143.

Naor, A., Cohen, S., 2003. Sensitivity and variability of maximum trunk shrinkage, midday stem water potential, and transpiration rate in response to withholding irrigation from field-grown apple trees. HortScience 38 (4), 547-551.

Naor, A., 2006a. Irrigation scheduling and evaluation of tree water status in deciduous orchards. Hortic. Rev. 32, 111-165.

Naor, A., Gal, Y., Peres, M., 2006b. The inherent variability of water stress indicators in apple, nectarine and pear orchards, and the validity of a leaf-selection procedure for water potential measurements. Irrig. Sci. 24 (2), 129-135.

Naor, A., Naschitz, S., Peres, M., Gal, Y., 2008. Responses of apple fruit size to tree water status and crop load. Tree Physiol. 28, 1255-1261.

Naor, A., 2012. Apple. In FAO Irrigation and Drainage Paper No 66, Crop Yield Response to Water. pp. 332-345.

Padilla-Díaz, C.M., Rodriguez-Dominguez, C.M., Hernandez-Santana, V., Perez-Martin A., Fernández, J.E., 2016. Scheduling regulated deficit irrigation in a hedgerow olive orchard from leaf turgor pressure related measurements. Agric. Water Manag. 164, 28-37.

Scalisi, A., Bresilla, K., Grilo, F.S., 2017. Continuous determination of fruit tree waterstatus by plant-based sensors. Italus Hortus 24 (2), 39-50.

Scholander, P.F., Bradstreet, E.D., Hemmingsen, E.A., Hammel, H.T., 1965. Sap pressure in vascular plants negative hydrostatic pressure can be measured in plants. Science 148, 339-346.

Thalheimer, M., 2016. A new optoelectronic sensor for monitoring fruit or stem radial growth. Comp. Electr. Agric. 123, 149-153.

Turner, N.C., Long, M.J., 1980. Errors arising from rapid water loss in the measurements of leaf water potential by the pressure chamber technique. Austral. J. Plant Physiol. 7, 527-537.

Zar, J.H., 1984. Multiple comparisons. Biostatistical Analysis, second ed. PRENTICEHALL, INC., Englewood Cliffs, New Jersey, pp. 190-191.

Zhang, L.-Y., Peng, Y.-B., Pelleschi-Travier, S., Fan, Y., Lu, Y.-F., Lu, Y.-M., Gao, X.-P., Shen, Y.-Y., Delrot, S., Zhang, D.-P., 2004. Evidence for apoplasmic phloem unloading in developing apple fruit. Plant Physiol. 135 (1), 574-586. https://doi.org/ 10.1104/pp.103.036632.

Zimmerman, D., Reuss, R., Westhoff, M., Geßner, P., Bauer, W., Bamberg, E., Bentrup, F. W., Zimmermann, U., 2008. A novel, non-invasive, online-monitoring, versatile and easy plant-based probe for measuring leaf water status. J. Exp. Bot. 59, 3157-3167. www.hkconsulting.it. 